\title{
PENGARUH HARD-SOFT SKILL DAN DISIPLIN KERJA TERHADAP KINERJA TENAGA PENDIDIK DI SMK NEGERI 1 PASAMAN
}

\author{
${ }^{1}$ Endang Tirtana Putra \\ ${ }^{2}$ Nur Anita \\ Program Studi Manajemen, Sekolah Tinggi Ilmu Ekonomi Pasaman \\ Email: endangtirtanaputra@gmail.com¹anitanur575@yahoo.com²
}

\begin{abstract}
ABSTRAK
Peran sumber daya manusia adalah untuk mencapai tujuan perusahaan yang sudah ditetapkan sebelumnya secara efektif dan efisien. Pendidikan adalah berbagai upaya dan usaha yang dilakukan orang dewasa untuk mendidik nalar peserta didik dan mengatur moral mereka. Untuk mewujudkan itu semua, tak terlepas dari Kinerja seorang Tenaga Pendidik dalam suatu satuan Pendidikan. Hard-Soft Skill, dan Disiplin Kerja bertujuan untuk membuktikan secara empiris Kinerja Tenaga Pendidik di SMK Negeri 1 Pasaman. Jenis kausalitas digunakan pada penelitian ini dengan pendeketan analisis kuantitatif. Populasi penelitian ini adalah seluruh Tenaga Pendidik SMK Negeri 1 Pasaman. Pengambilan sampel digunakan teknik sampel sensus yaitu melibatkan keseluruhan populasi lima puluh tenaga pendidik. Analisis data menggunakan teknik regresi linier berganda. Hasil penelitian menemukan bahwa: 1). Terdapat pengaruh signifikan atas variabel Hard-Soft Skill terhadap variabel Kinerja Tenaga Pendidik. 2) Tidak terdapat pengaruh atas variabel Disiplin Kerja terhadap Kinerja Tenaga Pendidik. 3) Terdapat pengaruh signifikan atas variabel Hard-Soft Skill dan Disiplin Kerja secara simultan terhadap variabel Kinerja Tenaga Pendidik. 4) Koefisien determinasi menghasilkan skor 0,902, artinya, besarnya kontribusi faktor Hard-Soft Skill dan Disiplin Kerja terhadap Kinerja Tenaga Pendidik sangat kuat yaitu 90,2 persen.
\end{abstract}

Kata kunci: Hard-Soft Skill, Kinerja Tenaga Pendidik.

\begin{abstract}
The role of human resources is to effectively and efficiently achieve predetermined corporate goals. Education is the efforts and efforts made by adults to educate students' reasoning and regulate their morals. To make it all happen, it cannot be separated from an Teacher's Performance in an education unit. Hard-Soft Skills and Work Discipline aim to empirically prove the Teacher's Performance at SMK Negeri 1 Pasaman. This type of causality is used in this study with a quantitative analysis approach. The population of this study was all teaching staff at SMK Negeri 1 Pasaman. Sampling used a census sampling technique that involves fifty educators' entire population-data analysis using multiple linear regression techniques. The research found that: 1). There is a significant influence on the Hard-Soft Skill variable on the Teacher's Performance variable. 2) There is no influence on the Work Discipline variable on the Teacher's Performance. 3) There is a significant influence on the variable Hard-Soft Skill and Work Discipline simultaneously on the Teacher's Performance variable. 4) The coefficient of determination produces a score of 0.902, which means that the Hard-Soft Skill Skill and Work Discipline factors to the Teacher's Performance are powerful, namely 90.2 percent.
\end{abstract}

Keyword Hard-Soft Skill, Teacher's Performance 


\section{PENDAHULUAN}

Sumberdaya manusia ini sangat besar pengaruhnya bagi suatu organisasi atau perusahaan, baik perusahaan yang berorientasi pada keuntungan seperti, perusahaan swasta maupun perusahaan instansi pemerintah yang sebagian besar tidak berorientasi pada keuntungan. Peran sumber daya manusia adalah untuk mencapai tujuan perusahaan yang sudah ditetapkan sebelumnya secara efektif dan efisien. Tujuan pokok sumber daya manusia untuk mewujudkan pendayagunaan sumberdaya manusia secara optimal di dalam suatu organisasai atau perusahaan (Ismanto, 2014). Pendidikan adalah upaya sadar dan terencana untuk menciptakan suasana belajar dan proses pembelajaran agar peserta didik secara aktif mengembangkan potensinya untuk memiliki kekuatan spiritual-religius, penguasaan diri, kepribadian, kecerdasan, akhlak mulia, dan keterampilan yang dibutuhkan dirinya, masyarakat, bangsa, dan negara bagian (Mirnawati, 2017). Menurut Undang-Undang Republik Indonesia Nomor 20 Tahun 2003 tentang Sistem Pendidikan Nasional, prinsip penyelenggaraan pendidikan harus sesuai dengan tujuan pendidikan nasional yaitu; mengembangkan kemampuan dan membentuk watak serta peradaban bangsa yang bermartabat dalam rangka mencerdaskan kehidupan bangsa, bertujuan untuk berkembangnya potensi peserta didik agar menjadi manusia yang beriman dan bertakwa kepada Tuhan Yang Maha Esa, berakhlak mulia, sehat, berilmu, cakap, kreatif, mandiri, dan menjadi warga negara yang demokratis serta bertanggung jawab (Erda, 2020).

Pendidikan adalah berbagai upaya dan usaha yang dilakukan orang dewasa untuk mendidik nalar peserta didik dan mengatur moral mereka. Untuk mewujudkan itu semua, tak terlepas dari Kinerja seorang Tenaga Pendidik dalam suatu satuan Pendidikan (Sukring, 2016). Organisasi dalam penyusunan personalia guru atau fungsi SDM harus juga mampu menjalankan aktivitas tahapan recruitment calon karyawan agar memenuhi spesifikasi yang diinginkan bagi penggunanya (Husain, 2017). Untuk mempengaruhi kinerja seorang Tenaga Pendidik juga dibutuhkan peran seorang pemimpin sangat berpengaruh dan beberapa faktor penting lainnya. Dalam beberapa pengertian organisasi ditegaskan adanya kepemimpinan yang merupakan salah satu faktor organisasi. Organization is an united group of people working for common goal, under common leadership, and with the proper tools, atau dengan menggunakan istilah singkatnya organisasi adalah sekelompok yang bersatupadu bekerja untuk satu tujuan bersama, dibawah kepemimpinan bersama dan dengan alat-alat yang tepat (Price, 2006, hal. 255).

Kompetensi guru menghasilkan output dari proses belajar yang efektif dari kombinasi komponen akal sehat, pengetahuan, dan penguasaan materi pelajaran, keterampilan mengajar, 
semangat dan kepribadian yang kuat, penilaian siswa yang adil dan obyektif, serta kerja keras (Quintania, 2019). Guru dapat menjadi raw model karyawan, asumsi ini jika dikaitkan dan memiliki prosedur maupun kebijakan atas suksesi kepemimpinan melalui mekanisme pengembangan karir (career development). Di samping itu, karyawan dengan fungsi tenaga pengajar (guru) dalam organisasi dituntut memberikan pelayanan yang terbaik dengan mengedepankan perluasan usaha atau dengan kata lain saluran distribusi talen keluar organisasi yang dimiliki (Sudaryana, 2020). Sedarmayanti (2018) mendefinisikan bahwa kinerja merupakan kata atau istilah 'performance' yang artinya hasil kerja seorang pekerja, sebuah proses manajemen atau suatu organisasi secara keseluruhan, dimana hasil kerja tersebut harus dapat ditunjukkan buktinya secara konkrit dan dapat diukur. Transfer knowledge yang baik dan perbaikan berkesinambungan juga akan secara tidak langsung meningkatkan kualitas pelayanan seorang tenaga pendidik atau pengajar (Elmie, Fadli, \& Faddila, 2020). Saat ini dengan peningkatan kemajuan teknologi dan kecanggihan perangkat atau media, para tenaga pendidik dituntut untuk memiliki kemampuan baik itu hard skill maupun soft skill. Kondisi ini dapat diterapkan misalnya dengan menggunakan platform komputasi awan dan infrastruktur yang difokuskan dalam mengelola dan mengkoordinasikan sumber daya data secara efektif untuk mencapai skala tertentu (Husain \& Budiyantara, 2020).

Keunggulan suasana persaingan dalam berbisnis memiliki peran yang signifikan dalam membantu meningkatkan produktivitas dan kinerja. Pemberdayaan kesadaran bersaing dengan keterlibatan kooperatif untuk memahami dengan jelas pedoman inti dan pandangan yang memiliki wawasan dan berperan kunci secara strategis (Huda, et al., 2019). Peran kunci strategis ini terletak pada kemampuan hardskill maupun soft skill bagi sumberdaya manusia dalam organisasi khususnya bagi seorang tenaga pendidik (guru). Lebih lanjut, kinerja guru yang baik dan profesionalisme yang ditunjukkan guru yang terdiri dari penguasaan 4 (empat) kompetensi diantaranya kompetensi profesional, kompetensi pedagogis, kompetensi kepribadian dan aspek sosial (Handayani \& Rasyid, 2015). Tenaga pendidik merupakan salah satu penunjang dan penentu keberhasilan dalam proses pembelajaran. Apabila tenaga pendidik memiliki mutu yang baik dalam proses pembelajaran maka hal tersebut akan dapat menjadi sebab untuk tercapainya target proses pembelajaran dan secara tidak langsung dapat meningkatkan kinerja.

Beberapa sekolah di Sumatera Barat masih dihadapkan persoalan khusus seperti kinerja tenaga pendidik dalam mencapai target tertentu yang diberikan organisasi sekolah seperti halnya dengan SMK Negeri 1 Pasaman yang secara umum dikatakan sudah cukup baik, hal ini dibuktikan dengan banyaknya prestasi yang diperoleh oleh para peserta didik, baik prestasi 
yang diperoleh di tingkat Kabupaten Pasaman Barat maupun tingkat Provinsi Sumatera Barat. Meskipun dengan prestasi yang bagus tersebut, namun masih banyak hal-hal yang perlu ditingkatkan lagi agar kinerja para tenaga pendidik lebih baik lagi kedepannya. Saat ini masih banyak guru yang belum mampu mengoperasikan komputer/laptop dengan baik, belum bisa menggunakan media pembelajaran dengan baik misalnya LCD Proyektor. Hal ini merupakan salah satu hard skill yang hendaknya dimiliki oleh seorang tenaga pendidik di zaman modern sekarang ini sehingga para siswa/i lebih mampu menerima pelajaran dengan baik.

Hasil penelitian terdahulu yang dikaji antara lain: 1) Prestasi kinerja karyawan pada PT. Hasjrat Abadi Menado ayng dipengaruhi oleh disiplin kerja, pelatihan dan kemampuan kerja (soft skill dan hard skill) yang melibatkan sampel sebanyak 58 responden, dengan temuan penelitian yang secara parsial membuktikan pengaruh disiplin kerja, pelatihan dan kemampuan kerja (soft skill dan hard skill) terhadap prestasi kerja karyawan (Logor, Tumade, \& Wenas, 2015). 2) Penelitian untuk menganalisis softskill dan hardskill terhadap Kinerja Siswa Prakerin SMK Modern Al - Rifa'ie Gondanglegi Malang yang melibatkan 52 orang responden Siswa Prakerin SMK Modern Al - Rifa'ie Tahun Pelajaran 2012/2013 dan Tahun Ajaran 2013/2014, dengan temuan hasil yang menjelaskan pengaruh yang erat dan signifikan atas variabel hardskill terhadap kinerja siswa (Nuryana, 2015). 3) Hubungan hard skill, soft skill dan pengalaman kerja dengan kinerja karyawan pada 45 karyawan perpustakaan Universitas Sanata Dharma, dengan temuan penelitian yaitu hard dan soft skill secara parsial memiliki hubungan sementara pengalaman kerja tidak memiliki hubungan yang signifikan dengan kinerja karyawan (Rusady, 2016). 4) Kinerja Guru yang dipengaruhi Sikap Inovatif, Kedisiplinan Dan Motivasi Kerja yang melibatkan 111 sampel guru SMP Negeri seKecamatan Sleman, dengan hasil penelitian yaitu hanya sikap inovatif yang berpengaruh positif dan signifikan sementara kedisiplinan dan motivasi kerja tidak berpengaruh signifikan terhadap kinerja guru SMP Negeri se-Kecamatan Sleman (Wachidah, 2019).

Soft skill dan hard skill adalah integrasi yaitu softskill yang berdampak pada fungsi hard skills yang dimiliki. Soft skills dapat menjadi determinan arah pemanfaatan hard skills, jika seseorang memilikinya dengan baik, maka ilmu dan keterampilan yang dikuasainya dapat mendatangkan kesejahteraan dan kenyamanan bagi pemiliknya dan lingkungannya (Nuryana, 2015). Soft skill itu sendiri menurut Islami adalah keterampilan seseorang dalam berhubungan dengan orang lain (interpersonal skills) dan keterampilan dalam mengatur dirinya sendiri (intrapersonal skills) yang mampu mengembangkan unjuk kerja secara maksimal (Rusady, 2016). Menurut Peggy Klaus (2007), soft skills mencakup perilaku personal, sosial, komunikasi, dan manajemen diri, mencakup spektrum yang luas: kesadaran 
diri, kepercayaan, kesadaran, kemampuan beradaptasi, pemikiran kritis, organisasi (Nuryana, 2015).

Hard skills menurut Shivanjali (2010) adalah kemampuan khusus yang dapat diajarkan yang mungkin diperlukan dalam konteks tertentu, seperti pelatihan kerja, yang akan membantu seseorang untuk menjalankan profesinya sebagai dasar dan fundamental karena membantu individu untuk mengembangkan pengetahuan dalam domain tertentu. Kemampuan untuk mengajar yang memerlukan sebuah konteks, semisal pelatihan kerja, yang akan membantu seseorang untuk mengemban pekerjaannya (Nuryana, 2015). Hard skills menjadi suatu keistimewaan dalam pengembangan teknologi yang dimiliki dalam kompetensi seorang pekerja dengan pendekatan ini dapat mengatasi persoalan yang terjadi dan mengidentifikasi ide-ide baru mengenai produk atau jasa. Organisasi menilai bahwa penetapan kriteria hard skill merujuk pada gambaran dari kualitas karyawan yang dimiliki organisasi pada konsumennya yang memberikan pertimbangan positif terhadap organisasi dimana karyawan memenuhi kriteria atau kualitas yang sesungguhnya (Rusady, 2016). Pendidik yang tidak kompeten akan mengalami kesulitan dalam menyampaikan isi materi yang akan diajarkan dalam proses pembelajaran di kelas (Sukring, 2016). Hard skill sering juga disebut dengan kemampuan intelektual (intellectuallability) yang merujuk pada kemampuan yang dibutuhkan untuk menentukan berbagai aktivitas mental berpikir, menalar dan memecahkan masalah (Rivai, 2015, hal. 28).

Kinerja tenaga pendidik juga tidak terlepas dari faktor disiplin kerja dalam mencapai produktivitasnya. Disiplin kerja menurut Rivai (2015:825), merupakan alat yang digunakan para manajer untuk berkomunikasi dengan karyawan agar mereka bersedia untuk mengubah suatu perilaku sebagai suatu upaya untuk meningkatkan kesadaran dan kesediaan seseorang mematuhi semua peraturan perusahaan dan norma-norma sosial yang berlaku. Disiplin adalah sikap menaati peraturan yang berlaku, baik secara tertulis maupun tidak tertulis serta sanggup menjalankannya dan tidak menolak untuk menerima sanksi-sanksi apabila dia melanggar tugas dan wewenang yang diberikan (Hasibuan, 2017, hal. 123). Menurut Mangkunegara (2017), pelaksanaan tugas seorang karyawan dalam mencapai hasil kerja baik secara kuantitas maupun kualitas atas dasar tanggungjawab yang diberikan kepadanya (Sudaryana, 2020). Disiplin kerja yang tinggi akan mampu membangun kinerja profesional, karena pemahaman disiplin yang baik guru mampu mencermati aturan-aturan dan langkah strategis dalam melaksanakan proses kegiatan belajar mengajar.

Kedisiplinan bagi guru merupakan bagian yang tidak dapat dipisahkan dalam melaksanakan tugas dan kewajibannya di samping guru sebagai tenaga pendidik 
membutuhkan soft-hard skills. Dengan adanya masalah kinerja tenaga pendidik yang melekat pada individu di SMK Negeri 1 Pasaman dan beberapa temuan hasil penelitian sebelumnya yang tidak konsisten. Penelitian ini bertujuan untuk mengkaji dan membuktikan secara empiris pengaruh Hard Skill, Soft Skill dan Disiplin Kerja terhadap Kinerja Tenaga Pendidik. Penelitian ini diharapkan dapat memberikan sumbangsih keilmuan khususnya pada guru-guru di SMK Negeri 1 Pasaman, Padang dalam meningkatkan kinerjanya.

\section{METODE PENELITIAN}

\section{Jenis Penelitian}

Jenis kausalitas digunakan pada penelitian ini yang didefinisikan sebagai penelitian dengan karakteristik berupa hubungan yang bersifat sebab akibat antara variabel independen (Sugiyono, 2017, hal. 62). Pendekatan penelitian kuantitatif digunakan melalui riset survei melalui observasi dan hasilnya diukur menggunakan data primer berupa persepsi kepada responden. Analisis ini bertujuan untuk mengevaluasi sifat psikometri kuesioner untuk memahami instrumen yang berkaitan dengan responsivitas dan kognisi responden (Sani et al., 2020). Tujuan yang ingin dibangun adalah evaluasi berdasarkan interpretasi responden dan investigasi menggunakan sudut pandang peneliti atas kinerja tenaga pendidik berdasarkan perangkat tersebut.

\section{Waktu dan Tempat Penelitian}

Penelitian ini dilakukan pada tahun 2020 pada institusi pada SMK Negeril Pasaman, yang berdomisili di Jalan Pertanian Padang Tujuah, Kabupaten Pasaman Barat, Provinsi Sumatera Barat.

\section{Target/Subjek Penelitian}

Subjek penelitian melibatkan 50 orang Tenaga Pendidik di SMK Negeri 1 Pasaman dengan metode sampel sensus. Sampel sensus adalah teknik penentuan sampel bila semua anggota populasi digunakan sebagai sampel (Sugiyono, 2017, hal. 78).

\section{Data, Instrumen, dan Teknik Pengumpulan Data}

Data menggunakan kategori data primer yang berupa persepsi responden, yaitu Tenaga Pendidik. Instrumen menggunakan perangkat (tools) berupa kuesioner atau angket. Kuesioner ini diukur dan diukur dengan menggunakan skala Likert (Kaptein, Nass, \& Markopoulos, 2010; Sani, Wiliani, \& Husain, 2019). Skala Likert ditetapkan dengan 5 (lima) gradasi dari tingkat sangat tidak setuju sampai dengan setuju (Sugiyono, 2017). Teknik pengumpulan data 
menggunakan konsep tertutup yaitu angket yang disajikan dalam bentuk seperangkat pernyataan tertulis kepada responden untuk dijawab.

\section{Teknik Analisis Data}

Analisis data menggunakan teknik persamaan regresi linier berganda untuk menguji hipotesis dilakukan pada taraf nyata 5 persen. Data dianalisis menggunakan bantuan perangkat lunak SPSS. Adapun persamaan regresi yang dibentuk adalah:

$$
y=a+b \mathrm{X} 1+b \mathrm{X} 2+b \mathrm{X} 3+e
$$

\section{HASIL PENELITIAN DAN PEMBAHASAN}

\section{Hasil Penelitian}

Kinerja Tenaga Pendidik merupakan variabel terikat (dependent) yang diukur melalui 10 (sepuluh) butir pernyataan. Hard Skill dan Soft Skill masing-masing diukur melalui 13 (tiga belas) dan 10 (sepuluh) butir pertanyaan. Disiplin kerja diukur melalui 10 (sepuluh) butir pernyataan. Ketiganya merupakan variabel bebas (independent).

Tabel 1 Hasil Uji Validitas Data

\begin{tabular}{llcc}
\hline No & \multicolumn{1}{c}{ Pernyataan } & $\begin{array}{c}\text { Item-Total } \\
\text { Correlation }\end{array}$ & $\begin{array}{c}\text { Hasil } \\
\text { Uji }\end{array}$ \\
\hline Variabel Dependen: Kinerja Tenaga Pendidik & & \\
\hline 1 & Saya mampu menyelesaikan semua pekerjaan yang ditugaskan & 0,347 & Valid \\
\hline 2 & Skill yang saya miliki sesuai dengan pekerjaan yang di kerjakan & 0,850 & Valid \\
\hline 3 & Saya melakukan pekerjaan dengan penuh perhitungan & 0,822 & Valid \\
\hline 4 & $\begin{array}{l}\text { Saya memanfaatkan waktu sebaik mungkin untuk } \\
\text { menyelesaikan pekerjaaan }\end{array}$ & 0,850 & Valid \\
\hline 5 & Saya mampu tidak membiasakan diri untuk menunda pekerjaan & 0,770 & Valid \\
\hline 6 & $\begin{array}{l}\text { Saya memaksimalkan sumber daya yang ada dalam } \\
\text { menyelesaikan pekerjaan }\end{array}$ & 0,825 & Valid \\
\hline 7 & Saya menyelesaikan pekerjaan yang menjadi tugas pokok & 0,825 & Valid \\
\hline & $\begin{array}{l}\text { Saya mengerjakan tugas pokok yang diembankan kepada saya } \\
\text { dengan penuh rasa tanggung jawab tanpa harus disuruh terlebih } \\
\text { dahulu }\end{array}$ & 0,850 & Valid \\
\hline 9 & $\begin{array}{l}\text { Saya berkomitmen dan bertanggung jawab dalam melaksanakan } \\
\text { tugas yang ada }\end{array}$ & 0,770 & Valid \\
\hline 10 & Saya bekerja sesuai dengan koridor struktur & 0,822 & Valid \\
\hline \multicolumn{4}{c}{ Variabel Independen: Hard Skill } \\
\hline 1 & $\begin{array}{l}\text { Saya memiliki keahlian menggunakan angka dengan baik } \\
\text { dan penalaran yang benar }\end{array}$ & 0,567 & Valid \\
\hline 2 & $\begin{array}{l}\text { Sebagai Tenaga Pendidik, saya memiliki kemampuan } \\
\text { menghitung secara matematik }\end{array}$ & 0,627 & Valid \\
\hline 3 & $\begin{array}{l}\text { Saya memiliki kemampuan verbal untuk belajar berbicara, } \\
\text { untuk memahami pembicaraan }\end{array}$ & 0,783 & Valid \\
\hline & \multicolumn{1}{c}{0,0} \\
\hline
\end{tabular}




\begin{tabular}{|c|c|c|c|}
\hline No & Pernyataan & $\begin{array}{l}\text { Item-Total } \\
\text { Correlation }\end{array}$ & $\begin{array}{c}\text { Hasil } \\
\text { Uji }\end{array}$ \\
\hline 4 & $\begin{array}{l}\text { Saya memiliki kemampuan di dalam membaca dan menulis } \\
\text { dengan baik }\end{array}$ & 0,706 & Valid \\
\hline 5 & $\begin{array}{l}\text { Sebagai Tenaga Pendidik, Pimpinan dapat menilai tindakan } \\
\text { saya baik apabila tindakan tersebut sesuai dengan yang } \\
\text { diharapkan }\end{array}$ & 0,571 & Valid \\
\hline 6 & Saya memiliki anggapan yang positif terhadap pekerjaan & 0,594 & Valid \\
\hline 7 & $\begin{array}{l}\text { Sebagai Tenaga Pendidik, semakin tinggi derajat kesamaan } \\
\text { persepsi antar sesama Tenaga Pendidik, maka semakin mudah } \\
\text { mereka berkomunikasi }\end{array}$ & 0,567 & Valid \\
\hline 8 & $\begin{array}{l}\text { Saya selalu berfikir mengembangkan atau mengendalikan } \\
\text { pekerjaan dengan nalar, dan bukan dengan perasaan atau } \\
\text { pengalaman }\end{array}$ & 0,627 & Valid \\
\hline 9 & $\begin{array}{l}\text { Saya melakukan penalaran dengan mengambil contoh khusus } \\
\text { yang khas untuk mengilustrasikan suatu masalah }\end{array}$ & 0,783 & Valid \\
\hline 10 & $\begin{array}{l}\text { Saya bekerja menggunakan logika dalam menyelesaikan suatu } \\
\text { masalah }\end{array}$ & 0,706 & Valid \\
\hline 11 & $\begin{array}{l}\text { Sebagai Tenaga Pendidik, kebanyakan kegagalan terjadi } \\
\text { karena mempunyai karakter suka menundapekerjaan }\end{array}$ & 0,571 & Valid \\
\hline 12 & Saya mampu mengenali setiap masalah ketika bekerja & 0,783 & Valid \\
\hline 13 & $\begin{array}{l}\text { Kebiasaan secara berulang-ulang akan membantu saya } \\
\text { mengingat apa saja untuk jangka waktu yang lama }\end{array}$ & 0,339 & Valid \\
\hline \multicolumn{4}{|c|}{ Variabel Independen: Soft Skill } \\
\hline 1 & Saya bertanggung jawab terhadap pekerjaanyang diberikan & 0,676 & Valid \\
\hline 2 & $\begin{array}{l}\text { Saya juga bertanggung jawab terhadap keadaan lingkungan } \\
\text { kerja }\end{array}$ & 0,654 & Valid \\
\hline 3 & Saya memiliki rasa percaya diri dalam menyelesaikan masalah & 0,818 & Valid \\
\hline 4 & Saya memiliki rasa percaya diri dalam meningkatkan karir & 0,423 & Valid \\
\hline 5 & $\begin{array}{l}\text { Saya mampu mengatur diri sendiri dalam mentaati segala } \\
\text { peraturan yang berlaku }\end{array}$ & 0,703 & Valid \\
\hline 6 & $\begin{array}{l}\text { Saya mampu mengatur diri sendiri yang tidak terlepas dari } \\
\text { tingkat emosi diri }\end{array}$ & 0,653 & Valid \\
\hline 7 & Saya membina sosialisasi yang baik antar karyawan & 0,445 & Valid \\
\hline 8 & $\begin{array}{l}\text { Saya selalu bersosialisasi menyelesaikan masalah dengan } \\
\text { atasan }\end{array}$ & 0,818 & Valid \\
\hline 9 & $\begin{array}{l}\text { Setiap Tenaga Pendidik saling berbagi informasi kepada rekan } \\
\text { kerja }\end{array}$ & 0,524 & Valid \\
\hline 10 & $\begin{array}{l}\text { Setiap Tenaga Pendidik mau berbagi ilmu dengan orang lain } \\
\text { mengenai pekerjaan }\end{array}$ & 0,358 & Valid \\
\hline \multicolumn{4}{|c|}{ Variabel Independen: Disiplin Kerja } \\
\hline 1 & $\begin{array}{l}\text { Peraturan jam kerja, baik jam masuk dan jam pulang harus } \\
\text { efektif bagi suatu Instansi/Organisasi }\end{array}$ & 0,724 & Valid \\
\hline 2 & $\begin{array}{l}\text { Sistem pendataan kehadiran di Instansi saya bekerja sudah } \\
\text { efektif }\end{array}$ & 0,540 & Valid \\
\hline 3 & $\begin{array}{l}\text { Saya selalu disiplin dalam memakai pakaian seragam dan } \\
\text { atribut pegawai }\end{array}$ & 0,692 & Valid \\
\hline 4 & $\begin{array}{l}\text { Saya selalu berbicara dengan penuh sopan dan santun baik } \\
\text { kepada siswa/i, sesama rekan kerja maupun kepada pimpinan }\end{array}$ & 0,724 & Valid \\
\hline
\end{tabular}




\begin{tabular}{llcc}
\hline No & \multicolumn{1}{c}{ Pernyataan } & $\begin{array}{c}\text { Item-Total } \\
\text { Correlation }\end{array}$ & $\begin{array}{c}\text { Hasil } \\
\text { Uji }\end{array}$ \\
\hline 5 & $\begin{array}{l}\text { Saya selalu menaati segala aturan yang ada ditempat saya } \\
\text { bekerja }\end{array}$ & 0,640 & Valid \\
\hline 6 & Saya dituntut untuk bekerja dengan baik & 0,547 & Valid \\
\hline 7 & $\begin{array}{l}\text { Saya selalu menaati segala aturan yang ada ditempat saya } \\
\text { bekerja }\end{array}$ & 0,588 & Valid \\
\hline 8 & $\begin{array}{l}\text { Saya berusaha untuk melaksanakan pekerjaan dan tugas sesuai } \\
\text { dengan posisi dan fungsi }\end{array}$ & 0,540 & Valid \\
\hline 9 & $\begin{array}{l}\text { Atasan akan memberikan teguran apabila pekerjaan tidak } \\
\text { dapat diselesaikan }\end{array}$ & 0,692 & Valid \\
\hline 10 & Perintah yang diberikan oleh atasan langsung harus dikerjakan & 0,692 & Valid \\
\hline
\end{tabular}

Lampiran Pengolahan Data (2020)

Dari tabel 1 di atas, dilihat bahwa nilai corrected item-total correlation semua butir pernyataan berkisar antara 0,347 - 0,850, masing-masing pengukuran Hard Skill, Soft Skill, dan Disiplin Kerja memiliki nilai skor yang lebih besar dari 0,30, artinya butir pernyataan tersebut semuanya dinyatakan valid.

Tabel 2 Hasil Uji Reliabilitas Data

\begin{tabular}{llcl}
\hline Variabel & $\begin{array}{l}\text { Jumlah } \\
\text { Item }\end{array}$ & $\begin{array}{l}\text { Cronbach's } \\
\text { Alpha }\end{array}$ & Keterangan \\
\hline Kinerja Tenaga Pendidik $(Y)$ & 10 & 0.944 & Reliabel \\
Hard Skill $\left(\mathrm{X}_{1}\right)$ & 13 & 0,908 & Reliabel \\
Soft Skill $\left(\mathrm{X}_{2}\right)$ & 10 & 0,876 & Reliabel \\
Disiplin Kerja $\left(\mathrm{X}_{3}\right)$ & 10 & 0,895 & Reliabel \\
\hline
\end{tabular}

Lampiran Pengolahan Data (2020)

Dari tabel 2 di atas, terlihat hasil pengujian reliabilitas data untuk semua variabel yang digunakan dalam penelitian ini reliabel karena memiliki nilai cronbach's Alpha $>0.60$. Ini menunjukkan bahwa instrument yang digunakan untuk semua variabel tersebut adalah handal.Uji asumsi klasik yang pertama dilakukan sebagai syarat yang harus terpenuhi dalam analisis regresi. Bila data yang dianalis tidak berdistribusi normal, maka analisis regresi tidak dapat terpenuhi. Jika nilai signifikansi $<0.05$ distribusi data adalah tidak normal dan sebaliknya jika nilai signifikansi $\geq 0.05$ distribusi data adalah normal.

Tabel 3 Hasil Uji Normalitas

\begin{tabular}{lcl}
\hline Variabel & $\begin{array}{c}\text { Probabilitas } \\
\text { Signifikansi }\end{array}$ & Keterangan \\
\hline Kinerja Tenaga Pendidik $(\mathrm{Y})$ & 0,152 & masing-masing \\
Hard Skill $\left(\mathrm{X}_{1}\right)$ & 0,546 & memiliki skor $>0,05$, \\
Soft Skill $\left(\mathrm{X}_{2}\right)$ & 0,476 & maka berdistribusi \\
\hline
\end{tabular}




\begin{tabular}{lcl}
\hline Variabel & $\begin{array}{l}\text { Probabilitas } \\
\text { Signifikansi }\end{array}$ & Keterangan \\
\hline Disiplin Kerja $\left(\mathrm{X}_{3}\right)$ & 0,645 & normal \\
\hline Lampiran Pengolahan Data $(2020)$ & &
\end{tabular}

Lampiran Pengolahan Data (2020)

Dari tabel 3 di atas, terlihat bahwa seluruh data menunjukan kondisi yang normal sehingga dari segi normalitas data memenuhi syarat untuk dilakukan analisa data dengan regresi. Pengujian linieritas digunakan untuk melihat apakah spesifikasi model yang digunakan sudah benar atau tidak. Apabila titik-titik distribusi mengikuti garis linier, maka model regresi dapat dinyatakan linier, dalam penelitian ini, untuk uji linieritas menggunakan grafik P-P. Plot.

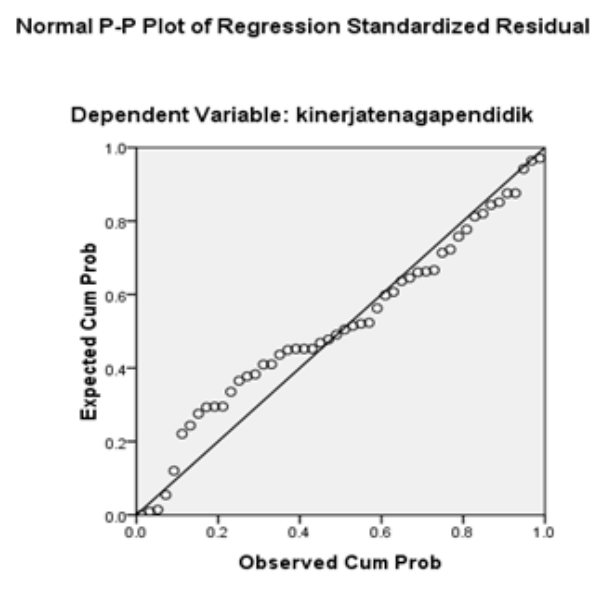

Gambar 1 Hasil Uji Linieritas

Berdasarkan grafik tersebut diatas terlihat bahwa titik-titik bergerak menuju searah garis linier. Hal ini dapat disimpulkan bahwa model regresi dalam penelitian ini adalah linier.

Uji heteroskedastisitas berguna untuk menguji apakah variasi kelompok populasi homogeny atau tidak. Jika variasi kelompok populasi satu pengamatan ke pengamatan lain tetap, maka disebut 'homoskedastisitas' dan jika berbeda disebut 'heterokedastisitas'. Model regresi yang baik adalah homoskedastisitas atau tidak terjadi heteroskedastisitas.

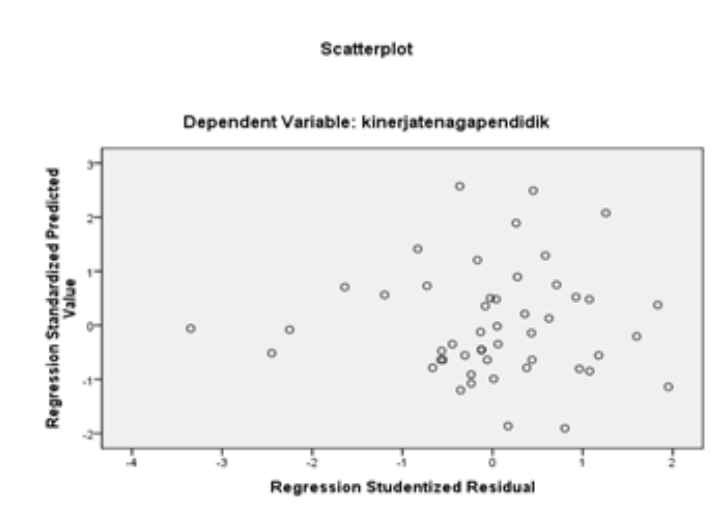

Gambar 2 Hasil Uji Heteroskedastisitas 
Berdasarkan grafik scatterplot di atas, tidak ditemukan terbentuknya pola-pola tertentu dari penyebaran titik-titik pada grafik. Oleh karena itu dapat disimpulkan bahwa model regresi dalam penelitian ini adalah homoskedastisitas atau tidak terjadi heteroskedastisitas.

Sebelum menggunakan analisis regresi linear berganda terlebih dahulu dilakukan Uji Multikolinearitas, untuk menghindari agar antara variabel independen tidak berkorelasi sesamanya. Hubungan masing-masing variabel ditunjukka dengan melihat nilai VIF (Varians Inflation Factor). Bila skor tolerance $>0,1$ atau nilai $\mathrm{VIF}<10$, maka terdapat gejala multikolinearitas.

Tabel 4 Hasil Uji Multikolinearitas

\begin{tabular}{lccl}
\hline Variabel & Skor Tolerance & Skor VIF & Keterangan \\
\hline Hard Skill $\left(\mathrm{X}_{1}\right)$ & 0,129 & 4,927 & masing-masing memiliki skor \\
Soft Skill $\left(\mathrm{X}_{2}\right)$ & 0,320 & 3,123 & tolerance $>0,1$, dan VIF $<10$ \\
Disiplin Kerja $\left(\mathrm{X}_{3}\right)$ & 0,128 & 6,261 & maka tidak terjadi multikolinearitas \\
\hline
\end{tabular}

Lampiran Pengolahan Data (2020)

Tabel 5 Ringkasan Hasil Analisis Regresi Linier Berganda

\begin{tabular}{lllll}
\hline Variabel Independen & Koefisien & t Hitung & Sig & Ket. \\
\hline Konstanta & 0,767 & 3,723 & 0.001 & - \\
\hline Hard Skill (X1) & 1,803 & 5,789 & 0,000 & Signifikan \\
\hline Soft Skill (X2) & -0.882 & $-9,445$ & 0,000 & Signifikan \\
\hline Disiplin Kerja (X3) & $-0,127$ & $-0,409$ & .0685 & Tidak Signifikan \\
\hline Koefisien Korelasi (R): 0,950 & & & & \\
Koefisien Determinasi ( $\left.{ }^{2}\right): 0,902$ & & & \\
Nilai F: 141,404 & & & \\
Signifikan F: 0,000 & & & \\
\hline Lampiran Pengolahan Data (2020) & & &
\end{tabular}

Dari tabel 5 di atas, ringkasan analisis regresi linier berganda digunakan untuk mengetahui hipotesis secara persial, yaitu untuk melihat pengaruh dari masing - masing variabel bebas terhadap variabel terikat. Model penelitian memiliki nilai signifikansi F lebih kecil dari alpha $5 \%(0,000<0,05)$. Dengan demikian dapat dikatakan bahwa model regresi yang ada sudah baik dan layak digunakan dalam penelitian ini. Dengan kata lain Hard-Soft Skill dan Disiplin Kerja secara simultan berpengaruh signifikan terhadap Kinerja Tenaga Pendidik. Nilai koefisien determinasi menunjukkan persentase variasi nilai variabel dependen yang dapat dijelaskan oleh persamaan regresi yang dihasilkan koefisien determinasi bertujuan untuk mengetahui signifikan variabel. Koefisien determinasi berkisar antara 0 (nol) sampai dengan 1 (satu), $(0 \leq \mathrm{R} 2 \leq 1)$. Nilai R-Square, adalah 0,902 artinya model semakin kuat untuk 
menerangkan pengaruh variabel Hard-Soft Skill dan Disiplin Kerja untuk menjelaskan kontribusinya terhadap Kinerja Tenaga Pendidik sebesar 90,2 persen.

\section{Pembahasan}

Berdasarkan hasil pengujian hipotesis diketahui bahwa masing-masing Hard-Soft Skill memiliki pengaruh yang signifikan terhadap Kinerja Tenaga Pendidik dengan besaran koefisien regresi untuk hard skill sebesar 1,803, artinya jika hard skill meningkat maka nilai Kinerja Tenaga Pendidik akan meningkat dan begitu juga sebaliknya. Sementara besaran koefisien regresi untuk soft skill sebesar minus 0,882, artinya jika soft skill meningkat maka nilai Kinerja Tenaga Pendidik akan menurun dan begitu juga sebaliknya sebaliknya. Apabila seorang Tenaga Pendidik di SMK Negeri 1 Pasaman memiliki Hard Skill yang baik dan bagus, maka hal ini akan mendorong kinerjanya menjadi jauh lebih baik karena Hard Skill memiliki pengaruh yang besar terhadap kinerja seorang tenaga pendidik yang menjadi sampel penelitian, namun jika sebaliknya jika Hard Skill seorang tenaga pendidik itu rendah dan kurang baik, maka hal ini juga akan menurunkan kinerja dari Tenaga Pendidik itu sendiri. Akan tetapi berlawanan dengan Soft Skill yang dimiliki tenaga pendidik yang berlawanan dengan Hard Skill namun kinerja tenaga pendidik, artinya masih bisa baik dan bagus meski tanpa Soft Skill yang mumpuni sekalipun. Dalam fakta nyata dilapangan juga terlihat bahwa sesorang yang tidak memiliki. Soft skill menjadi penting karena dalam komunitas learning center yang merupakan sekumpulan kemampuan yang mempengaruhi cara orang berinteraksi dengan orang lain meliputi komunikasi yang efektif, pemikiran kreatif dan kritis, pembangunan tim, dan keterampilan lain yang terkait dengan kapasitas kepribadian individu (Rismayadi, Moeins, Herdinalis, \& Sovitriana, 2017). Soft Skill yang baikpun misalnya dalam hal berinteraksi dengan orang lain masih bisa memiliki kinerja yang bagus karena Soft Skill merupakan bawaan dari dalam diri seseorang dimana pada sebagian orang ada yang lebih suka untuk mengerjakan saja apa yang dibebankan kepada dia tanpa peduli dan peka terhadap lingkungan. Penelitian ini sejalan dengan bukti empiris atas kemampuan kerja (soft skill dan hard skill) pada prestasi kerja (Logor, Tumade, \& Wenas, 2015), pengaruh yang erat dan signifikan atas variabel hardskill terhadap kinerja siswa (Nuryana, 2015), dan penelitian yang menggunakan hard dan soft skill secara parsial memiliki hubungan dengan kinerja karyawan (Rusady, 2016).

Berdasarkan hasil pengujian hipotesis diketahui bahwa Disiplin Kerja tidak memiliki pengaruh yang signifikan terhadap Kinerja Tenaga Pendidik dengan besaran koefisien regresi sebesar minus 0,127, artinya jika disiplin kerja menurun maka nilai Kinerja Tenaga Pendidik 
akan meningkat tetapi tidak signifikan atau meskipun seorang tenaga pendidik tidak disiplin, namun kinerjanya masih bisa baik dan bagus yang menjadi sampel penelitian yaitu tenaga pendidik di SMK Negeri 1 Pasaman. Penelitian ini sejalan dengan bukti empiris atas tidak signifikannya pengaruh disiplin kerja terhadap prestasi kinerja karyawan (Logor, Tumade, \& Wenas, 2015), pengalaman kerja terhadap kinerja karyawan (Rusady, 2016), dan kedisiplinan dan motivasi kerja tidak berpengaruh signifikan terhadap kinerja guru SMP Negeri seKecamatan Sleman (Wachidah, 2019).

\section{KESIMPULAN DAN IMPLIKASI}

Kesimpulan dari penelitian ini yaitu 1) Hard-Soft Skill berpengaruh signifikan dengan arah positif pada hard skill sementara arah negatif pada soft skill terhadap Kinerja Tenaga Pendidik di SMK Negeri 1 Pasaman. 2) Disiplin Kerja tidak berpengaruh signifikan dengan arah negatif terhadap Kinerja Tenaga Pendidik di SMK Negeri 1 Pasaman. 3) Hard-Soft Skill dan Disiplin Kerja berpengaruh signifikan secara simultan dan sangat kuat menerangkan atau berkontribusi pada Kinerja Tenaga Pendidik sebesar 90,2 persen di SMK Negeri 1 Pasaman. Hasil penelitian ini penting untuk mencermati kinerja tenaga pendidik khususnya di Sekolah Menengah Atas berstatus Negeri bahwa Hard Skill namun kinerja tenaga pendidik masih bisa baik dan bagus meski tanpa Soft Skill yang baik sekalipun dan peningkatan kapasitas guru sebagai tenaga pendidik Soft Skill diperlukan melalui program perencanaan kari, pelatihan serta bimbingan teknis agar mampu kompeten dan eksis dalam menghadapi kemajuan teknologi yang sangat cepat.

\section{DAFTAR PUSTAKA}

Elmie, Fadli, U. M., \& Faddila, S. P. (2020). Pengaruh Lingkungan Kerja, Kompetensi Dosen, dan Kualitas Layanan terhadap Citra Perguruan Tinggi. Jurnal Manajemen \& Bisnis Kreatif, 6(1), 72-80. https://doi.org/10.36805/manajemen.v6i1.1190

Erda. (2020, Juni 26). Pentingnya Pendidikan Karakter bagi Peserta Didik. Retrieved Desember 2020, from: https://jamberita.com/read/2020/06/26/5959893/pentingnyapendidikan-karakter-bagi-peserta-didik/

Handayani, T., \& Rasyid, A. A. (2015). Pengaruh Kepemimpinan Kepala Sekolah, Motivasi Guru, dan Budaya Organisasi terhadap Kinerja Guru SMA Negeri Wonosobo. Jurnal Akuntabilitas Manajemen Pendidikan. 3(2), 264-277. https://doi.org/10.21831/amp.v3i2.6342

Hasibuan, M. S. (2017). Manajemen Sumber Daya Manusia (Cetakan ke-18) (Revisi ed.). Jakarta: PT Bumi Aksara.

Huda, M., Qodriah, S. L., Rismayadi, B., Hananto, A., Kardiyati, E. N., Ruskam, A., et al. (2019). Towards Cooperative With Competitive Alliance: Insights Into Performance Value in Social Entrepreneurship. In N. O. Iyigun, Creating Business Value and 
Competitive Advantage With Social Entrepreneurship (pp. 294-317). Pennsylvania, Amerika: IGI Global. https://doi.org/10.4018/978-1-5225-5687-9.ch014

Husain, T. (2017). Rancang Bangun Sistem Informasi Perekrutan Calon Guru Baru Di SMPIT Pesantren Nururrahman. Jurnal Cendikia, 15(2), 1-6.

Husain, T., \& Budiyantara, A. (2020). Analysis of Control Security and Privacy Based on eLearning Users. SAR Journal, 3(2), 51-58. https://doi.org/10.18421/SAR32-01

Ismanto, Y. (2014). Manajemen Sumber Daya Manusia. In Konsep Dasar Manajemen Sumber Daya Manusia (MSDM) (pp. 1-51). Jakarta: Universitas Terbuka.

Kaptein, M. C., Nass, C., \& Markopoulos, P. (2010). Powerful and consistent analysis of likert-type rating scales. In E. Mynatt (Ed.), CHI '10: Proceedings of the SIGCHI Conference on Human Factors in Computing Systems (pp. 2391-2394). Atlanta Georgia USA: SIGCHI. https://doi.org/10.1145/1753326.1753686

Klaus, P., Rohman, J. M., \& Hamaker, M. (2007). The Hard Truth About Soft Skills: Soft Skills for Succeeding in a Hard Wor (Kindle ed.). New York: HarperCollins.

Logor, F. B., Tumade, P., \& Wenas, R. (2015). Pengaruh Disiplin Kerja, Pelatihan, Dan Kemampuan Kerja Terhadap Prestasi Kerja Karyawan Pada PT. Hasjrat Abadi Manado. Jurnal EMBA: Jurnal Riset Ekonomi, Manajemen, Bisnis dan Akuntansi, 3(3), 1151-1161. https://doi.org/10.35794/emba.v3i3.10120

Mirnawati, L. B. (2017). Pengaruh Model Pembelajaran Kooperatif Tipe Group Investigation terhadap Kreativitas Mahasiswa Semester I PGSD UM Surabaya pada Mata Kuliah Pengantar Manajemen Pendidikan. Pedagogia: Jurnal Pendidikan, 6(1), 84-97. http://dx.doi.org/10.21070/pedagogia.v6i1.598

Nuryana, I. (2015). Pengaruh Softskill dan Hardskill terhadap Kinerja Siswa Prakerin SMK Modern Al-Rifa'ie (Studi pada Siswa Prakerin SMK Modern Al-Rifa'ie Gondanglegi). Referensi: Jurnal Ilmu Manajemen dan Akuntansi, 3(2), 40-48. https://doi.org/10.33366/ref.v3i2.807

Price, W. (2006). Patofisiologi Vol 2; Konsep Kllinis Proses-proses Penyakit. Jakarta: Penerbit Buku Kedokteran.

Quintania, M. (2019). The Relationships between Teacher Competence, School Facilities, Competence of Dormitory Tutors and Dormitory Facilities According to the Student Perceptions and Performance (Case Study on SMP Kharisma Boarding School, Tangerang - Banten). European Exploratory Scientific Journal, 3(3), 1-8. https://syniutajournals.com/index.php/EESJ/article/view/145/128

Rismayadi, B., Moeins, A., Herdinalis, \& Sovitriana, R. (2017). The Influence of Organizational Culture, Soft Skill, and Leadership on Organizational Commitment and its implication at educator Performance (Empirical Reaserch on Community Learning Center Karawang District, West Java Indonesia). International Journal of Applied Business and Economic Research, 15(20), 111-131.

Rivai, V. (2015). Manajemen Sumber Daya Manusia Untuk Perusahaan: Dari Teori ke Praktik (3 ed.). Jakarta: PT. Raja Grafindo Persada.

Rusady, F. B. (2016). Hubungan Hard Skill, Soft Skill, dan Pengalaman Kerja dengan Kinerja Karyawan. Yogyakarta: Universitas Sanata Dharma.

Sani, A., Pusparini, N. N., Rizal, R., Khristiana, Y., Zailani, A. U., \& Husain, T. (2020). EBusiness Adoption Models in Organizational Contexts on The TAM Extended Model: A Preliminary Assessment. 8th International Conference on Cyber and IT Service Management (CITSM 2020). Pangkalpinang: UIN Syarif Hidayatullah. https://ieeexplore.iee.org/abstract/document/9268869/

Sani, A., Wiliani, N., \& Husain, T. (2019). Spreadsheet Usability Testing in Nielsen's Model among Users of ITSMEs to Improve Company Performance. European Journal of Scientific Exploration, 2(6), 1-9. 
Sedarmayanti. (2018). Manajemen Sumber Daya Manusia: Reformasi Birokrasi, dan Manajemen Pegawai Negeri Sipil. Bandung: Reflika Aditama.

Shivanjali. (2010). Soft Skills Training Versus Hard Skills Training. International Journal in Multidisciplinary and Academic Research (SSIJMAR), 1(3).

Sudaryana, Y. (2020). Effect Of Compensation And Career Development To The Employee Performance (Study At PT. Benesse Indonesia). Journal of Management Review, 4(2), 491-500. http://dx.doi.org/10.25157/mr.v4i2.3470

Sugiyono. (2017). Metode Penelitian Evaluasi: Pendekatan Kuantitatif, Kualitatif, dan Kombinasi. Bandung: CV. Alfabeta.

Sukring. (2016). Pendidik dalam Pengembangan Kecerdasan Peserta Didik (Analisis Perspektif Pendidikan Islam). Tadris: Jurnal Keguruan dan Ilmu Tarbiyah, 01(1), 6980.

Undang-Undang Republik Indonesia Nomor 20 Tahun 2003 tentang Sistem Pendidikan Nasional.

Wachidah, N. (2019). Pengaruh Sikap Inovatif, Kedisiplinan dan Motivasi Kerja Terhadap Kinerja Guru SMP Negeri. Journal of Educational Evaluation Studies (JEES), 1(1), 57-63. 